\title{
Improvements in quality of life associated with biphasic insulin aspart 30 in type 2 diabetes patients in China: results from the $A_{1}$ chieve $^{\oplus}$ observational study
}

Wenying Yang ${ }^{1}$, Xiaoming Zhuang ${ }^{2}$, Yukun $\mathrm{Li}^{3}$, Qing Wang ${ }^{4}$, Rongwen Bian ${ }^{5}$, Jianguo Shen ${ }^{6}$, Eva Hammerby ${ }^{7}$ and Li Yang ${ }^{8^{*}}$

\begin{abstract}
Background: Based on the 24-week, prospective, non-interventional, observational study, $A_{1}$ chieve $^{\varpi}$, we investigated how health-related quality of life (HRQOL) changed, and the predictors of such changes, in Chinese people with type 2 diabetes mellitus (T2DM) after starting with, or switching to, biphasic insulin aspart 30 (BIAsp 30).

Methods: In total, 8,578 people with T2DM starting treatment with, or switching to, BIAsp 30 were recruited from 130 urban hospitals in China. HRQoL was assessed at baseline and 24 weeks using the EuroQol-5 dimensions (EQ-5D) questionnaire. Descriptive statistics, paired $t$-test, and chi-square test were conducted and the linear ordinary least squares regression model was used to determine predictors for changes in EQ-5D score.

Results: Haemoglobin $\mathrm{A}_{1 c}\left(\mathrm{HbA}_{1 c}\right)$ decreased from 9.5\% to $7.0 \%$ after 24 weeks. The reported HRQoL measured by the EQ-5D visual analogue scale score increased by 6.2 ( $p<0.001)$ from 75.8 to 82.0, and EQ-5D index score increased by 0.018 ( $p<0.001$ ) from 0.875 to 0.893 for the cohort over 24 weeks. The percentage of patients reporting no problems in the mobility, pain/discomfort, and anxiety/depression dimensions of EQ-5D increased significantly $(p<0.001)$ from $88.4 \%$ to $91.4 \%, 77.3 \%$ to $82.8 \%$, and $74.2 \%$ to $77.1 \%$, respectively. Patients with higher HbA1c levels at baseline, major hypoglycaemia or micro-complications exhibited significantly larger changes in EQ-5D scores than those with lower baseline HbA1c levels, without major hypoglycaemia or micro-complications after controlling for demographics and other baseline characteristics.
\end{abstract}

Conclusions: BIAsp 30 treatment was associated with improved glycaemic control and HRQoL in T2DM patients in China. Patients with worse health conditions were more likely to experience larger improvements in HRQoL than those with better health conditions.

Trial registration: ClinicalTrials.gov, NCT00869908.

Keywords: Quality of life, Biphasic insulin aspart 30, Type 2 diabetes, Chinese setting, Observational, EQ-5D

\footnotetext{
* Correspondence: lyang@hsc.pku.edu.cn

${ }^{8}$ Department of Health Policy and Management, School of Public Health, Peking University, No 38 Xueyuan Rd. Haidian District, Beijing 100191, China Full list of author information is available at the end of the article
} 


\section{Background}

Globally, the number of people with diabetes has increased at an alarming level, and diabetes is placing a heavy economic burden on families and healthcare systems. The number of people with diabetes was estimated at more than 371 million in 2012, and is expected to be 551.9 million in 2030 [1]. China has become the country with the largest number of people with diabetes in the world. The most recent study estimated that the prevalence of diabetes among a representative sample of Chinese adults was $11.6 \%$ and the prevalence of pre-diabetes was 50.1\%, which corresponded to 113.9 million and 493.4 million people, respectively, in 2010 [2]. The Chinese Diabetes Society of the Chinese Medical Association and International Diabetes Federation estimated that 13\% of total medical expenditures in China were directly caused by diabetes in 2010 [3].

Diabetes is a debilitating disease characterized by deficiencies in insulin secretion, insulin action, or both, leading to chronic hyperglycaemia [4]. Insulin treatment is the inevitable choice for people with type 2 diabetes (T2DM) as diabetes progresses. It is typically used after glycaemic control fails or is not maintained with lifestyle changes and combinations of oral anti-diabetic medications [5]. Insulin treatment can improve glycaemic control, prevent the development of long-term complications of diabetes [6], and influence patients' quality of life [7].

There are a few studies concerning the impacts of insulin use on patients' health-related quality of life (HRQoL), with the impacts recorded ranging from positive [8-10] to negative [11-13]. There are no studies regarding whether insulin therapy improves or decreases patients' quality of life in a Chinese setting. The purpose of this study was to assess how HRQoL changed, and the predictors of such changes, after starting with, or switching to, biphasic insulin aspart 30 (BIAsp 30, 30\% soluble insulin aspart, $70 \%$ protamine-crystallized insulin aspart) over a 24-week period among people with T2DM in China using Chinese subgroup data from the $\mathrm{A}_{1}$ chieve $^{\oplus}$, study [14].

\section{Methods}

\section{Study design}

$\mathrm{A}_{1}$ chieve $^{\oplus}$ was a 24-week, international, prospective, multicentre, non-interventional, observational study of people with T2DM in non-Western countries who had begun using basal insulin detemir, bolus insulin aspart and premixed insulin BIAsp 30, alone or in combination [14]. It was the largest observational study ever conducted in insulin therapy and was carried out in 28 countries across four continents (Asia, Africa, South America and Europe). Individuals with type 2 diabetes with no prior history of using the study insulins previously, and who had been started on one of the insulins in the 4 weeks prior to the study start are eligible for this study. People with hypersensitivity to the study insulins or excipients, and women who were pregnant, breast feeding, or who intended to become pregnant within 6 months of the study are excluded. The therapies were prescribed by the physicians in the course of normal clinical practice and treatment demand rather than randomly assigned by the researchers. The study was conducted in accordance with the Declaration of Helsinki. The ethics committee approval was obtained for each country, and all participants gave written, informed consent prior to their inclusion in the study. In China, central ethics committee approval was performed in China-Japan Friendship Hospital. The coordinating sites accept the central ethics committee approval or further conduct the ethics committee approval by ethics committee of their own hospitals (Additional file 1).

The Chinese cohort that either started $(6,612)$ or were switched $(1,966)$ to BIAsp 30 in the $\mathrm{A}_{1}$ chieve ${ }^{\odot}$ study consisted of 8,578 people with T2DM from 130 urban hospitals in China. They were recruited between January 2009 and June 2010, and had an average observation period of six months. Approval from ethics committees were obtained at all the study sites.

\section{Clinical endpoints}

Clinical endpoints including safety and effectiveness outcomes were evaluated. Safety assessment included the incidence of serious adverse drug reactions (SADRs), including major hypoglycaemic events, the change in number of hypoglycaemic, the change in number of nocturnal hypoglycaemic event, and the number of adverse drug reactions (ADRs) from baseline to final visit. Effectiveness assessments included change in Haemoglobin A1c (HbA1c), fasting plasma glucose (FPG), postprandial plasma glucose (PPG), body weight between baseline and interim and final visits, and change in systolic blood pressure (SBP) and lipid profile at the final visit.

\section{HRQoL measurement}

The HRQoL was measured by the Chinese version of EQ$5 \mathrm{D}$ questionnaire at baseline and after 24 weeks of therapy. The EQ-5D consists of a descriptive system of five dimensions: mobility, self-care, usual activities, pain/discomfort, and anxiety/depression. Each of the five dimensions can take one of three responses recording different level of severity: no problems, some or moderate problems and extreme problems. These responses could be converted into a single utility value using the EQ-5D preference weights elicited from general population samples. The EQ$5 \mathrm{D}$ also includes a visual analogue scale (VAS) recording the respondents' direct valuation of their current HRQoL state on a graduated $(0-100)$ scale with higher scores for higher HRQoL [15]. The Chinese version of the EQ-5D 
Table 1 Characteristics of $A_{1}$ chieve ${ }^{\circledR}$ study respondents in insulin-naïve and insulin-experienced groups, and in the total cohort

\begin{tabular}{lllll}
\hline & & Insulin experienced $\mathbf{N}=\mathbf{1 9 6 6}$ & Insulin naïve $\mathbf{N}=\mathbf{6 6 1 2}$ & Total cohort $\mathbf{N}=\mathbf{8 5 7 8}$ \\
\hline Gender & Male, \% & $1104(56.2)$ & $3786(57.3)$ & $4890(57.0)$ \\
Age & Years, mean (sd) & $56.7(15.2)$ & $54.3(14.2)$ & $54.9(14.4)$ \\
Weight & $\mathrm{Kg}$, mean (sd) & $68.2(11.2)$ & $68.1(11.6)$ & $68.1(11.5)$ \\
BMl & $\mathrm{Kg} / \mathrm{m}^{2}$, mean (sd) & $24.8(3.3)$ & $24.6(3.3)$ & $24.7(3.3)$ \\
Duration of diabetes & Years, mean (sd) & $9.3(6.8)$ & $5.0(5.4)$ & $6.0(6.0)$ \\
\hline
\end{tabular}

was obtained from the EuroQol Group [16]. Its validity and reliability have been assessed in mainland China [17-19] and it has been used for studies of different populations in mainland China [20-22].

\section{Statistical analyses}

Descriptive analysis and multivariable regression were performed using SAS (Version 9.1.3, SAS Institute Inc., NC 27513-2414, USA). The change from baseline to 24 weeks in clinical endpoints, HRQoL with the EQ-5D VAS, and health utility value as continuous variables, were analysed with the Wilcoxon signed-rank test. The UK preference weights were used for calculation of EQ-
5D utility value because Chinese preference weights were still to be established.

The change in the percentage of people reporting no problem in EQ-5D descriptive dimensions was analysed with a chi-square test. For descriptive analysis, the total cohort was divided into subgroups of insulin-naïve people (those not taking insulin therapy at baseline) and previously insulin-experienced people (current insulin users). Linear OLS regression was further employed to explore predictors of the changes in EQ-5D score. Independent variables included patients' demographics (age and sex), health conditions (macro-complications, micro-complications, duration of diabetes, body mass index (BMI), $\mathrm{HbA}_{1 \mathrm{c}}, \mathrm{SBP}$,

Table $2 \mathrm{HbA}_{1 \mathrm{c}}$ body weight and hypoglycaemia in insulin-naïve and insulin-experienced patients, and in the total cohort

\begin{tabular}{|c|c|c|c|c|}
\hline & & Insulin-experienced, $\mathrm{N}=1,966$ & Insulin-naïve, $\mathrm{N}=6,612$ & Total cohort, $\mathrm{N}=\mathbf{8 , 5 7 8}$ \\
\hline \multirow[t]{5}{*}{$\mathrm{HbA}_{1 \mathrm{c}}(\%)$} & $\mathrm{N}$ & 1056 & 3386 & 4442 \\
\hline & Baseline & $9.1(2.3)$ & $9.6(2.2)$ & $9.5(2.3)$ \\
\hline & Week 24 & $7.0(1.1)$ & $7.0(1.0)$ & $7.0(1.0)$ \\
\hline & Change & $-2.0(2.2)$ & $-2.7(2.2)$ & $-2.5(2.2)$ \\
\hline & $P$ value & $<0.001$ & $<0.001$ & $<0.001$ \\
\hline \multirow[t]{5}{*}{ Body weight (kg) } & $\mathrm{N}$ & 1459 & 4600 & 6059 \\
\hline & Baseline & $68.7(11.2)$ & $68.5(11.3)$ & $68.5(11.3)$ \\
\hline & Week 24 & $69.2(10.9)$ & $68.8(10.8)$ & $68.9(10.8)$ \\
\hline & Change & $0.5(3.0)$ & $0.3(3.1)$ & $0.3(3.1)$ \\
\hline & $P$ value & $<0.001$ & $<0.001$ & $<0.001$ \\
\hline \multirow[t]{3}{*}{ Overall hypoglycaemia (events/patient year) } & $\mathrm{N}$ & 1966 & 6612 & 8578 \\
\hline & Baseline & 6.12 & 1.2 & 2.32 \\
\hline & Week 24 & 2.14 & 1.37 & 1.54 \\
\hline \multirow[t]{3}{*}{ Nocturnal hypoglycaemia (events/patient year) } & $\mathrm{N}$ & 1966 & 6612 & 8578 \\
\hline & Baseline & 1.65 & 0.26 & 0.58 \\
\hline & Week 24 & 0.42 & 0.24 & 0.28 \\
\hline \multirow[t]{3}{*}{ Major hypoglycaemia (events/patient year) } & N & 1966 & 6612 & 8578 \\
\hline & Baseline & 0.37 & 0.09 & 0.15 \\
\hline & Week 24 & 0.00 & 0.00 & 0.00 \\
\hline \multirow[t]{3}{*}{ Minor hypoglycaemia (events/patient year) } & $\mathrm{N}$ & 1966 & 6612 & 8578 \\
\hline & Baseline & 5.75 & 1.10 & 2.17 \\
\hline & Week 24 & 2.14 & 1.37 & 1.54 \\
\hline
\end{tabular}

Data are mean (sd), $\mathrm{n}$ or incidence. 
total cholesterol, high-density lipoprotein (HDL) and lowdensity lipoprotein (LDL)), and other related indicators (previous insulin experience, total hypoglycaemia and major hypoglycaemia) at baseline.

\section{Results}

\section{Demographics and characteristics of respondents}

Among the 8,578 people with T2DM, 1,966 (22.9\%) were in the insulin-experienced group and 6,612 (77.1\%) in the insulin-naïve group. The average age was $54.9( \pm 14.4)$ years, and BMI was $24.7( \pm 3.3) \mathrm{kg} / \mathrm{m}^{2}$ for the total cohort. The average duration of diabetes was $6.0( \pm 6.0)$ years, with $9.3( \pm 6.8)$ for the insulin-experienced group and $5.0( \pm 5.4)$ for the insulin-naïve group (Table 1).

\section{Clinical endpoints}

Blood glucose control measures improved markedly in both insulin-naïve and prior insulin users after 24 weeks of therapy with BIAsp 30. $\mathrm{HbA}_{1 \mathrm{c}}$ decreased from $9.5 \%$ to $7.0 \%$ for the total cohort, with a decrease from $9.1 \%$ to $7.0 \%$ for prior insulin users and a decrease from 9.6\% to $7.0 \%$ for the insulin-naïve group. From a similar baseline measure, body weight of the two groups increased slightly by $0.3 \mathrm{~kg}$ during the therapy. No major hypoglycaemia was observed during the study, and reported hypoglycaemia rates (including overall, nocturnal and minor hypoglycaemia) decreased in the total cohort and in both subgroups. All of these results indicated BIAsp 30 could improve blood glucose control without increasing the risk of hypoglycaemia

Table 3 Quality of life in insulin-naïve and insulin-experienced patients, and in the total cohort

\begin{tabular}{|c|c|c|c|c|}
\hline & & Insulin-experienced, $\mathrm{N}=1,966$ & Insulin-naïve, $\mathrm{N}=6,612$ & Total cohort, $\mathrm{N}=8,578$ \\
\hline \multirow[t]{5}{*}{ EQ-5D VAS (Scale 0-100) } & $\mathrm{N}$ & 1390 & 4713 & 6103 \\
\hline & Baseline & $75.3(14.1)$ & $75.9(13.4)$ & $75.8(13.6)$ \\
\hline & Week 24 & $82.0(11.3)$ & $82.0(10.3)$ & $82.0(10.6)$ \\
\hline & Change & $6.7(15.8)$ & $6.1(14.4)$ & $6.2(14.7)$ \\
\hline & $P$ value & $<0.001$ & $<0.001$ & $<0.001$ \\
\hline \multirow[t]{5}{*}{ QoL UK (Scale 0-1) } & N & 1406 & 4814 & 6220 \\
\hline & Baseline & $0.851(0.190)$ & $0.882(0.176)$ & $0.875(0.179)$ \\
\hline & Week 24 & $0.886(0.170)$ & $0.896(0.157)$ & $0.893(0.160)$ \\
\hline & Change & $0.035(0.228)$ & $0.014(0.218)$ & $0.018(0.221)$ \\
\hline & $P$ value & $<0.001$ & $<0.001$ & $<0.001$ \\
\hline Mobility dimension & $\mathrm{N}$ & 1416 & 4843 & 6259 \\
\hline \multirow[t]{3}{*}{ No problems with walking (\%) } & Baseline & $1197(84.5)$ & $4333(89.5)$ & $5530(88.4)$ \\
\hline & Week 24 & $1289(91.0)$ & $4433(91.5)$ & $5722(91.4)$ \\
\hline & $P$ value & $<0.0001$ & 0.0005 & $<0.0001$ \\
\hline Self-care dimension & N & 1415 & 4845 & 6260 \\
\hline \multirow[t]{3}{*}{ No problems with self-care (\%) } & Baseline & $1301(91.9)$ & $4475(92.4)$ & $5776(92.3)$ \\
\hline & Week 24 & $1280(90.5)$ & $4483(92.5)$ & $5763(92.1)$ \\
\hline & $P$ value & 0.1635 & 0.7584 & 0.6655 \\
\hline Usual activities dimension & $\mathrm{N}$ & 1415 & 4841 & 6256 \\
\hline \multirow[t]{3}{*}{ No problems with performing usual activities (\%) } & Baseline & $1222(86.4)$ & $4316(89.2)$ & $5538(88.5)$ \\
\hline & Week 24 & $1236(87.3)$ & $4272(88.2)$ & $5508(88.0)$ \\
\hline & $P$ value & 0.4361 & 0.1578 & 0.4043 \\
\hline Pain/discomfort dimension & N & 1411 & 4832 & 6243 \\
\hline \multirow[t]{3}{*}{ No pain or discomfort (\%) } & Baseline & $1007(71.4)$ & $3820(79.1)$ & $4827(77.3)$ \\
\hline & Week 24 & $1138(80.7)$ & $4031(83.4)$ & $5169(82.8)$ \\
\hline & $P$ value & $<0.0001$ & $<0.0001$ & $<0.0001$ \\
\hline Anxiety/depression dimension & $\mathrm{N}$ & 1413 & 4837 & 6250 \\
\hline \multirow[t]{3}{*}{ Not anxious or depressed (\%) } & Baseline & $1014(71.8)$ & $3624(74.9)$ & $4638(74.2)$ \\
\hline & Week 24 & $1067(75.5)$ & $3749(77.5)$ & $4816(77.1)$ \\
\hline & $P$ value & 0.0236 & 0.0028 & 0.0002 \\
\hline
\end{tabular}

Data are mean (sd), $\mathrm{n}$ or percentage. 
(Table 2). Indicators including FPG, PPG, SBP, LDL and HDL changed favourably, and no SADR was reported during the study period [23].

\section{Quality of life}

\section{Quality of life in the total cohort}

As measured by VAS from the EQ-5D (on a scale of $0-100)$, reported QoL of the total cohort increased by 6.2 from 75.8 at baseline to 82.0 at 24 weeks $(\mathrm{p}<0.001)$. The health utility value (on a scale of $0-1$ ) increased by 0.018 from 0.875 at baseline to 0.893 at 24 weeks $(\mathrm{p}<0.001)$.

The increased percentages of people reporting no problem on the descriptive EQ-5D dimensions indicated that there were improvements of HRQoL after BIAsp 30 treatment. The percentages of patients reporting no problems in three of the five dimensions of EQ-5D-mobility, pain/discomfort and anxiety/depression-increased significantly from $88.4 \%$ to $91.4 \%(\mathrm{p}<0.0001), 77.3 \%$ to $82.8 \%(\mathrm{p}<0.0001)$ and $74.2 \%$ to $77.1 \%(\mathrm{p}=0.002)$ after 24 weeks, respectively. There was no statistical significance found in the percentage of patients who reported no problems in self-care or who reported no problems in usual activities (Table 3).

\section{Quality of life for prior insulin-experienced and insulin-naïve subgroups}

Quality of life improved in both insulin-experienced and insulin-naïve patients. Baseline EQ-5D VAS scores were similar for both prior insulin-experienced and insulinnaive subgroups $(75.3,75.9)$. There was a significant increase in both subgroups after 24 weeks $(+15.8,+14.4$, $\mathrm{p}<0.001$ ). The baseline health utility value of the insulin-experienced group (0.851) was lower than that of the insulin-naïve group (0.882). After 24 weeks, the health utility value of the insulin-experienced and insulin-naive groups increased by $0.035(\mathrm{p}<0.001)$ and $0.014(\mathrm{p}<0.001)$ resulting in a similar health utility value between the two groups.

The percentages of patients reporting no problems in dimensions of mobility, pain/discomfort and anxiety/ depression increased significantly from $84.5 \%$ to $91.0 \%$ ( $\mathrm{p}<0.0001), 71.4 \%$ to $80.7 \%(\mathrm{p}<0.0001)$ and $71.8 \%$ to $75.5 \%$ (0.0236), respectively, for the prior insulinexperienced group, and from $89.5 \%$ to $91.5 \%(\mathrm{p}=0.0005)$, $79.1 \%$ to $83.4 \%(\mathrm{p}<0.0001)$ and $74.9 \%$ to $77.5 \%(\mathrm{p}=0.0028)$, respectively, for the insulin-naïve group. Decrease in percentages of patients reporting no problems were seen in the self-care dimension for the prior insulin-experienced group (from $91.9 \%$ to $90.5 \%$ ) and in the usual activities dimension (from $89.2 \%$ to $88.2 \%$ ) for the prior insulin-naïve group, but neither change was statistically significant. There were similar percentages of patients reporting no problems across all other dimensions between the two groups (Table 3).

\section{Linear OLS regression for the change in EQ-5D score}

Patients with higher $\mathrm{HbA}_{1 \mathrm{c}}$ levels at baseline, having major hypoglycaemia or micro-complications exhibited significantly larger changes in EQ-5D scores than those with lower baseline $\mathrm{HbA}_{1 \mathrm{c}}$ levels, without major hypoglycaemia or micro-complications after controlling for demographics and other baseline characteristics. HDL and LDL at baseline were negatively associated with change in EQ-5D scores. Other variables such as age, sex, duration of diabetes, and patients' prior insulin experience were not significantly associated with change in HRQoL (Table 4).

\section{Discussion}

This was the first study examining the impact of BIAsp 30 on HRQoL of people with T2DM in China. The result showed that people with T2DM starting with, or switching to, BIAsp 30 experienced significantly increased HRQoL over 24 weeks. The findings of this study were consistent with previous studies $[24,25]$ in other countries based on $\mathrm{A}_{1}$ chieve $^{\circ}$ that evaluated how patients' HRQoL changed after BIAsp 30 treatment.

The efficacy and safety of BIAsp 30 compared with other insulins were shown in randomized controlled trials [26-30], and the effectiveness of BIAsp 30 in near-routine clinical practice was demonstrated by observational studies $[31,32]$. This study extended the results from clinical outcomes of BIAsp 30 and added additional evidence for decision making by assessment of humanistic outcomes. HRQoL was considered as a multidimensional concept reflecting patients' subjective perceptions of their physical, mental and social functioning [33]. Measuring HRQoL

\section{Table 4 Multivariate linear regression for change in} EQ-5D VAS score

\begin{tabular}{lll}
\hline Variables & Coefficient & P-value \\
\hline Intercept & 5.4377 & 0.1041 \\
Macro-complications (yes $=1, \mathrm{no}=0$ ) & -0.6064 & 0.3188 \\
Micro-complications (yes $=1, \mathrm{no}=0$ ) & 1.4226 & 0.0067 \\
Duration of diabetes & 0.02993 & 0.5239 \\
Age & 0.02403 & 0.2699 \\
Male & -0.839 & 0.0944 \\
BMI at baseline & -0.1454 & 0.0554 \\
Pre_study treatment (Insulin naïve =1, & -0.5474 & 0.3547 \\
insulin users =0) & & \\
HbA ${ }_{1 c}$ at baseline & 0.3459 & 0.0013 \\
SBP at baseline & 0.0208 & 0.1661 \\
Total cholesterol at baseline & 0.4528 & 0.0817 \\
HDL at baseline & -2.3537 & $<.001$ \\
LDL at baseline & -0.7543 & 0.0138 \\
Total hypoglycaemia at baseline (yes = 1, no =0) & 0.01457 & 0.9628 \\
Major hypoglycaemia at baseline $(y e s=1$, no =0) & 6.957 & $<.001$ \\
\hline
\end{tabular}


provided a way to know patients' subjective perceptions of clinical practice, and allowed a comprehensive evaluation of the health intervention. There was evidence that proper assessment of HRQoL during healthcare management can result in improvements to the patients' health [34].

BIAsp30 treatment could be the most likely factor for improvements in HRQoL in this study. After treatment of BIAsp30, the patients' glycaemic control improved and rates of hypoglycaemic events decreased, and it is recognized both of these could lead to improvement in HRQoL $[35,36]$. However, since the $A_{1}$ chieve $^{\circ}$ was nonrandomised and lacked a standardised treatment proto$\mathrm{col}$, it should be noted that factors other than BIAsp 30 therapy itself could contribute to the improvements as well. The circumstances in which BIAsp 30 was started were unknown, and patients' self-management activities might be enhanced. Concomitant medication and dietary intake were not controlled either [14].

In addition to the impact of BIAsp 30 therapy on HRQoL, this paper also examined predictors for such impacts. The results of multivariable linear regression showed patients with a higher $\mathrm{HbA}_{1 \mathrm{c}}$ level, major hypoglycaemia or micro-complications at baseline experienced a larger amount of change in their EQ-5D scores. This finding indicates that patients with worse health conditions at baseline were more likely to experience larger improvements of HRQoL than those with better health conditions.

There were several limitations in this study. First, because evaluation of HRQoL was based on the observational $\mathrm{A}_{1}$ chieve ${ }^{\circ}$ study, which was non-randomised and lacked a standardised treatment protocol, confounding factors such as improvement of life style might affect patients' HRQol. Second, the UK preference weights used for utility calculations of EQ-5D in this study might differ from those of comparable Chinese weights and result in an inaccurate evaluation of change in HRQoL in Chinese people with T2DM. Moreover, although EQ-5D has been widely used in treatment evaluation for diabetes, disease-specific questionnaires are often regarded as more sensitive than generic measures such as EQ-5D for capturing the impact of treatment [6]. All of these issues leave room for future research.

\section{Conclusion}

This study suggested that BIAsp 30 treatment was associated with improved glycaemic control and HRQoL in people with T2DM in China. Patients with worse health conditions were more likely to experience larger improvements of HRQoL than those with better health conditions.

\section{Additional file}

Additional file 1: 130 hospitals and EC information for $A_{1}$ chieve study in China.

\section{Abbreviations}

EQ-5D: EuroQol-5 dimensions; HRQoL: Health-related quality of life; T2DM: Type 2 diabetes mellitus; BIAsp 30: Biphasic insulin aspart 30; SADR: Serious adverse drug reaction; ADR: Adverse drug reaction;

FPG: Fasting plasma glucose; PPG: Postprandial plasma glucose; SBP: Systolic blood pressure; VAS: Visual analogue scale; BMI: Body mass index; HDL: Highdensity lipoprotein; LDL: Low-density lipoprotein; $\mathrm{HbA}_{1 c}$ : Haemoglobin $A_{1 c}$.

\section{Competing interests}

This study was funded by National Science Foundation of China (71273016) and Young Foundation of Ministry of Education, Humanities and Social Science Research Projects (10YJC630332); The $A_{1}$ chieve ${ }^{\circledast}$ study was funded by Novo Nordisk (China) Pharmaceuticals Co., Ltd.

\section{Authors' contributions}

All authors advised on the design and conduct of the study. All authors reviewed the results of the study, and took part in writing and reviewing the manuscript. All authors read and approved the final manuscript.

\section{Acknowledgements}

The authors would like to thank all investigators involved in the $A_{1}$ chieve ${ }^{\bullet}$ study. The authors would like to thank Chunduo Shen of Novo Nordisk for providing statistical analyses.

\section{Author details}

${ }^{1}$ China-Japan Friendship Hospital, Beijing, China. ${ }^{2}$ Fu Xing Hospital, Capital Medical University, Beijing, China. ${ }^{3}$ The Third Hospital of Hebei Medical University, Hebei, China. ${ }^{4}$ Department of Endocrinology, China-Japan Union Hospital of Jilin University, Changchun, China. ${ }^{5}$ Jiangsu Provincial Official Hospital, Jiangsu, China. ${ }^{6}$ The First Affiliated Hospital, Zhejiang University, Zhejiang, China. ${ }^{7}$ Novo NordiskA/S, Copenhagen, Denmark. ${ }^{8}$ Department of Health Policy and Management, School of Public Health, Peking University, No 38 Xueyuan Rd. Haidian District, Beijing 100191, China.

Received: 22 December 2013 Accepted: 21 August 2014

Published online: 26 November 2014

\section{References}

1. International Diabetes Federation. Diabetes Atlas. 5th edition 2012 update. http://www.idf.org/diabetesatlas/5e/Update2012.

2. Xu Y, Wang L, He J, Bi Y, Li M, Wang T, Wang L, Jiang Y, Dai M, Lu J, Xu M, Li Y, Hu N, Li J, Mi S, Chen CS, Li G, Mu Y, Zhao J, Kong L, Chen J, Lai S, Wang W, Zhao W, Ning G, China Noncommunicable Disease Surveillance Group: Prevalence and control of diabetes in Chinese adults. JAMA 2010, 2013(310):948-958.

3. International Diabetes Federation: China spends RMB 173.4 billion (US\$25 billion) a year on diabetes treatment. http://www.idf.org/china-spends-rmb-1734-billionus25-billionyear-diabetes-treatment.

4. Wu N, Aagren M, Boulanger L, Friedman M, Wilkey K: Assessing achievement and maintenance of glycemic control by patients initiating basal insulin. Curr Med Res Opin 2012, 28:1647-1656.

5. Massi-Benedetti M, Orsini-Federici M: Treatment of type 2 diabetes with combined therapy: what are the pros and cons? Diabetes Care 2008, 31(Suppl 2):S131-S135.

6. Pouwer F, Hermanns N: Insulin therapy and quality of life. A review. Diabetes Metab Res Rev 2009, 25(Suppl 1):S4-S10.

7. Funnell MM: Quality of life and insulin therapy in type 2 diabetes mellitus. Insulin 2008, 3:31-36.

8. Vinik Al, Zhang Q: Adding insulin glargine versus rosiglitazone: healthrelated quality-of-life impact in type 2 diabetes. Diabetes Care 2007, 30:795-800.

9. Houlden R, Ross S, Harris S, Yale JF, Sauriol L, Gerstein HC: Treatment satisfaction and quality of life using an early insulinization strategy with insulin glargine compared to an adjusted oral therapy in the management of type 2 diabetes: the Canadian INSIGHT study. Diabetes Res Clin Pract 2007, 78:254-258.

10. Jacobson AM: Impact of improved glycemic control on quality of life in patients with diabetes. Endocr Pract 2004, 10:502-508.

11. Redekop WK, Koopmanschap MA, Stolk RP, Rutten GE, Wolffenbuttel BH, Niessen LW: Health related quality of life and treatment satisfaction in Dutch patients with type 2 diabetes. Diabetes Care 2002, 25:458-463. 
12. Davis RE, Morrissey M, Peters JR, Wittrup-Jensen K, Kennedy-Martin T, Currie CJ: Impact of hypoglycaemia on quality of life and productivity in type 1 and type 2 diabetes. Curr Med Res Opin 2005, 21:1477-1483.

13. Barendse S, Singh H, Frier BM, Speight J: The impact of hypoglycaemia on quality of life and related patient-reported outcomes in Type 2 diabetes: a narrative review. Diabet Med 2011, 29:293-302.

14. Shah SN, Litwak L, Haddad J, Chakkarwar PN, Hajjaji I: The $A_{1}$ chieve study: a 60 000-person, global, prospective, observational study of basal, meal-time, and biphasic insulin analogs in daily clinical practice. Diabetes Res Clin Pract 2010, 88(Suppl 1):S11-S16.

15. EuroQol Group: EuroQol-a new facility for the measurement of healthrelated quality of life. Health Policy 1990, 16:199-208.

16. EuroQol Group. http://www.euroqol.org/home.html.

17. Wang HM, Patrick DL, Edwards TC, Skalicky AM, Zeng HY, Gu WW: Validation of the EQ-5D in a general population sample in urban China. Qual Life Res 2012, 21:155-160.

18. Sun $S$, Chen J, Johannesson M, Kind $P, X u L$, Zhang $Y$, Burström $K$ : Population health status in China: EQ-5D results, by age, sex and socio-economic status, from the national health services survey 2008 Qual Life Res 2011, 20:309-320.

19. Wang $H$, Kindig DA, Mullahy J: Variation in Chinese population health related quality of life: results from a EuroQol study in Beijing, China. Qual Life Res 2005, 14:119-132.

20. Sheu WH, Ji LN, Nitiyanant W, Baik SH, Yin D, Mavros P, Chan SP: Hypoglycemia is associated with increased worry and lower quality of life among patients with type 2 diabetes treated with oral antihyperglycemic agents in the Asia-Pacific region. Diabetes Res Clin Pract 2012, 96:141-148.

21. Li H, Wei $X$, Ma A, Chung RY: Inequalities in health status among rural residents: EQ-5D findings from household survey China. Int J Equity Health 2014, 13:41-48.

22. Liang Y, Lu W, Wu W: Are social security policies for Chinese landless farmers really effective on health in the process of Chinese rapid urbanization? A study on the effect of social security policies for Chinese landless farmers on their health-related quality of life. Int J Equity Health 2014, 13:5-20.

23. Yang W, Li Y, Chen L, Shi Y, Peng Y, Lei M: Clinical use of daily biphasic insulin aspart 30 in Chinese people with type 2 diabetes: results of $A_{1}$ chieve observational study. Chin J Diabetes Mellitus 2012, 4:607-612.

24. Shah S, Zilov A, Malek R, Soewondo P, Bech O, Litwak L: Improvements in quality of life associated with insulin analogue therapies in people with type 2 diabetes: results from the $A_{1}$ chieve observational study. Diabetes Res Clin Pract 2011, 94:364-370.

25. Moses A, Chawla R, John W: Insulin analogue therapy improves quality of life in patients with type 2 diabetes in India: the A1chieve Study. J Assoc Phys India 2013, 61(Suppl.1):31-40.

26. Schmoelzer I, de Campo A, Pressl H, Stelzl H, Dittrich P, Oettl K: Biphasic insulin aspart compared to biphasic human insulin reduces postprandial hyperlipidemia in patients with type 2 diabetes. Exp Clin Endocrinol Diabetes 2005, 113:176-181.

27. McSorley PT, Bell PM, Jacobsen LV, Kristensen A, Lindholm A: Twice-daily biphasic insulin aspart 30 versus biphasic human insulin 30: a doubleblind crossover study in adults with type 2 diabetes mellitus. Clin Ther 2002, 24:530-539.

28. Tamemoto H, Ikoma A, Saitoh T, Ishikawa SE, Kawakami M: Comparison of once-daily glargine plus sulfonylurea with twice-daily 70/30 aspart premix in insulin-naive Japanese patients with diabetes. Diabetes Technol Ther 2007, 9:246-253.

29. Kilo C, Mezitis N, Jain R, Mersey J, McGill J, Raskin P: Starting patients with type 2 diabetes on insulin therapy using once-daily injections of biphasic insulin aspart 70/30, biphasic human insulin 70/30, or NPH insulin in combination with metformin. J Diabetes Complications 2003, 17:307-313.

30. Raskin P, Allen E, Hollander P, Lewin A, Gabbay RA, Hu P: Initiating insulin therapy in type 2 diabetes: a comparison of biphasic and basal insulin analogs. Diabetes Care 2005, 28:260-265.

31. Home H, Naggar NE, Khamseh M, Gonzalez-Galvez G, Shen C, Chakkarwar P: An observational non-interventional study of people with diabetes beginning or changed to insulin analogue therapy in non-Western countries: The $A_{1}$ chieve study. Diabetes Res Clin Pract 2011, 94:352-363.
32. Valensi $P$, Benroubi $M$, Borzi $V$ : Initiating insulin therapy with, or switching existing insulin therapy to, biphasic insulin aspart 30/70 (NovoMixR 30) in routine care: safety and effectiveness in patients with type 2 diabetes in the IMPROVETM observational study. Int J Clin Pract 2009, 63:522-531.

33. Rubin RR, Peyrot M: Quality of life and diabetes. Diabetes Metab Res Rev 1999, 15:205-218.

34. Magwood GS, Zapka J, Jenkins CA: Review of systematic reviews evaluating diabetes interventions: focus on quality of life and disparities. Diabetes Educ 2008, 34:242-265.

35. Zhang X, Norris SL, Chowdhury FM, Gregg EW, Zhang P: The effects of interventions on health-related quality of life among persons with diabetes: a systematic review. Med Care 2007, 45:820-834.

36. Barendse S, Singh H, Frier BM, Speight J: The impact of hypoglycaemia on quality of life and related patient-reported outcomes in Type 2 diabetes: a narrative review. Diabet Med 2012, 29:293-302.

doi:10.1186/s12955-014-0137-9

Cite this article as: Yang et al:: Improvements in quality of life associated with biphasic insulin aspart 30 in type 2 diabetes patients in China: results from the $A_{1}$ chieve ${ }^{\oplus}$ observational study. Health and Quality of Life Outcomes 2014 12:137.

\section{Submit your next manuscript to BioMed Central and take full advantage of:}

- Convenient online submission

- Thorough peer review

- No space constraints or color figure charges

- Immediate publication on acceptance

- Inclusion in PubMed, CAS, Scopus and Google Scholar

- Research which is freely available for redistribution
C) Biomed Central 